\title{
PROGNOSTIC EVALUATION OF PATIENTS WITH TRIPLE NEGATIVE IMMUNOPHENOTYPE, SUBMITTED TO NEOADJUVANT CHEMOTHERAPY
}

Fábio F. O. Rodrigues¹, Etiénne A. Bastos¹, Laís A. Inaba1', Eveline A. Silva1', Rodrigo M. Silva1', Carlos E. Fristachi ${ }^{1}$ Instituto do Câncer Doutor Arnaldo Vieira de Carvalho - São Paulo (SP), Brazil.

Objectives: Evaluate the characteristics of patients with triple negative (TN) submitted to neoadjuvant chemotherapy attended at the Dr Arnaldo Vieira de Carvalho Cancer Institute (ICAVC) from 2006 to 2012. Methods: A longitudinal study was performed, descriptive type, retrospective, of patients with invasive breast carcinoma attended at ICAVC in Sao Paulo; data were analyzed on the data base of Microsoft Excel ${ }^{\circledR}$. Results: Were evaluated 267 patients, among them, 24 (9\%) presented TN breast neoplasm by the immunohistochemical study; $21 \%$ of them underwent neoadjuvant chemotherapy, having as main regimens the association of anthracycline and taxane; $4 \%$ presented pathological complete response (pCR) and 29\% evolved with distant metastasis; being the disease free survival and mean global survival of 3 years calculed with Kaplan Meier. Conclusion: With this study, we observed 27\% of triple negative tumors that, differently from the literature, presented the small complete pathological responde index of only $4 \%$. 